NASA/TM-2008-215435

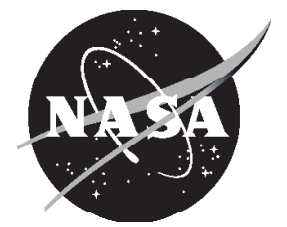

\title{
Structural Benchmark Creep Testing for the Advanced Stirling Convertor Heater Head
}

David L. Krause

Glenn Research Center, Cleveland, Ohio

Sreeramesh Kalluri

Ohio Aerospace Institute, Brook Park, Ohio

Randy R. Bowman

Glenn Research Center, Cleveland, Ohio

Ashwin R. Shah

Sest, Inc., Middleburg Heights, Ohio 


\section{NASA STI Program . . . in Profile}

Since its founding, NASA has been dedicated to the advancement of aeronautics and space science. The NASA Scientific and Technical Information (STI) program plays a key part in helping NASA maintain this important role.

The NASA STI Program operates under the auspices of the Agency Chief Information Officer. It collects, organizes, provides for archiving, and disseminates NASA's STI. The NASA STI program provides access to the NASA Aeronautics and Space Database and its public interface, the NASA Technical Reports Server, thus providing one of the largest collections of aeronautical and space science STI in the world. Results are published in both non-NASA channels and by NASA in the NASA STI Report Series, which includes the following report types:

- TECHNICAL PUBLICATION. Reports of completed research or a major significant phase of research that present the results of NASA programs and include extensive data or theoretical analysis. Includes compilations of significant scientific and technical data and information deemed to be of continuing reference value. NASA counterpart of peer-reviewed formal professional papers but has less stringent limitations on manuscript length and extent of graphic presentations.

- TECHNICAL MEMORANDUM. Scientific and technical findings that are preliminary or of specialized interest, e.g., quick release reports, working papers, and bibliographies that contain minimal annotation. Does not contain extensive analysis.

- CONTRACTOR REPORT. Scientific and technical findings by NASA-sponsored contractors and grantees.

- CONFERENCE PUBLICATION. Collected papers from scientific and technical conferences, symposia, seminars, or other meetings sponsored or cosponsored by NASA.

- SPECIAL PUBLICATION. Scientific, technical, or historical information from NASA programs, projects, and missions, often concerned with subjects having substantial public interest.

- TECHNICAL TRANSLATION. Englishlanguage translations of foreign scientific and technical material pertinent to NASA's mission.

Specialized services also include creating custom thesauri, building customized databases, organizing and publishing research results.

For more information about the NASA STI program, see the following:

- Access the NASA STI program home page at http://www.sti.nasa.gov

- E-mail your question via the Internet to help@ sti.nasa.gov

- Fax your question to the NASA STI Help Desk at 301-621-0134

- Telephone the NASA STI Help Desk at 301-621-0390

- Write to: NASA Center for AeroSpace Information (CASI) 7115 Standard Drive Hanover, MD 21076-1320 
NASA/TM-2008-215435

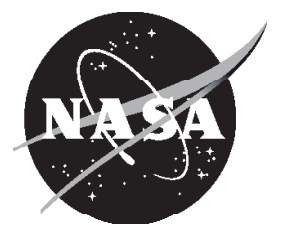

\section{Structural Benchmark Creep Testing for the Advanced Stirling Convertor Heater Head}

David L. Krause

Glenn Research Center, Cleveland, Ohio

Sreeramesh Kalluri

Ohio Aerospace Institute, Brook Park, Ohio

Randy R. Bowman

Glenn Research Center, Cleveland, Ohio

Ashwin R. Shah

Sest, Inc., Middleburg Heights, Ohio

Prepared for the

Sixth International Energy Conversion Engineering Conference (IECEC)

sponsored by the American Institute of Aeronautics and Astronautics

Cleveland, Ohio, July 28-30, 2008

National Aeronautics and

Space Administration

Glenn Research Center

Cleveland, Ohio 44135 


\section{Acknowledgments}

The authors appreciate and thank the inspiring leadership and program management at GRC provided by Dave Ercegovic, Dick Shaltens, Wayne Wong, Jeff Schreiber, and Lanny Thieme, as well as the full support and technical management of Drs. Gary Seng, Steven Arnold, and Michael Nathal. The authors also thank Ralph Pawlik and Frank Bremenour of their beneficial test engineering, technical collaboration, and able laboratory support for heater head benchmark testing. The Science Mission Directorate at NASA Headquarters provided funding to complete the work described herein, and the authors truly are grateful for that enduring commitment.

Trade names and trademarks are used in this report for identification only. Their usage does not constitute an official endorsement, either expressed or implied, by the National Aeronautics and Space Administration.

Level of Review: This material has been technically reviewed by technical management.

Available from

NASA Center for Aerospace Information 7115 Standard Drive

Hanover, MD 21076-1320
National Technical Information Service 5285 Port Royal Road Springfield, VA 22161 


\title{
Structural Benchmark Creep Testing for the Advanced Stirling Convertor Heater Head
}

\author{
David L. Krause \\ National Aeronautics and Space Administration \\ Glenn Research Center \\ Cleveland, Ohio 44135 \\ Sreeramesh Kalluri \\ Ohio Aerospace Institute \\ Brook Park, Ohio 44142 \\ Randy R. Bowman \\ National Aeronautics and Space Administration \\ Glenn Research Center \\ Cleveland, Ohio 44135 \\ Ashwin R. Shah \\ Sest, Inc. \\ Middleburg Heights, Ohio 44130
}

\begin{abstract}
The National Aeronautics and Space Administration (NASA) has identified the high efficiency Advanced Stirling Radioisotope Generator (ASRG) as a candidate power source for use on long duration Science missions such as lunar applications, Mars rovers, and deep space missions. For the inherent long life times required, a structurally significant design limit for the heater head component of the ASRG Advanced Stirling Convertor (ASC) is creep deformation induced at low stress levels and high temperatures. Demonstrating proof of adequate margins on creep deformation and rupture for the operating conditions and the MarM-247 material of construction is a challenge that the NASA Glenn Research Center is addressing. The combined analytical and experimental program ensures integrity and high reliability of the heater head for its 17-year design life. The life assessment approach starts with an extensive series of uniaxial creep tests on thin MarM-247 specimens that comprise the same chemistry, microstructure, and heat treatment processing as the heater head itself. This effort addresses a scarcity of openly available creep properties for the material as well as for the virtual absence of understanding of the effect on creep properties due to very thin walls, fine grains, low stress levels, and high-temperature fabrication steps. The approach continues with a considerable analytical effort, both deterministically to evaluate the median creep life using nonlinear finite element analysis, and probabilistically to calculate the heater head's reliability to a higher degree. Finally, the approach includes a substantial structural benchmark creep testing activity to calibrate and validate the analytical work. This last element provides high fidelity testing of prototypical heater head test articles; the testing includes the relevant material issues and the essential multiaxial stress state, and applies prototypical and accelerated temperature profiles for timely results in a highly controlled laboratory environment. This paper focuses on the last element and presents a preliminary methodology for creep rate prediction, the experimental methods, test challenges, and results from benchmark testing of a trial MarM-247 heater head test article. The results compare favorably with the analytical strain predictions. A description of other test findings is provided, and recommendations for future test procedures are suggested. The manuscript concludes with describing the potential impact of the heater head creep life assessment and benchmark testing effort on the ASC program.
\end{abstract}




\section{Introduction}

The Department of Energy (DOE) is planning to develop the Advanced Stirling Radioisotope Generator (ASRG) for the National Aeronautics and Space Administration (NASA) for potential use on future Science missions, such as lunar applications, Mars rovers, and deep space missions (refs. 1 to 3 ). Lockheed Martin Corporation of Valley Forge, Pennsylvania is the systems integrator, under contract to DOE. Sunpower, Inc. of Athens, Ohio is developing the Advanced Stirling Convertor (ASC) to be used in the ASRG under a NASA Research Announcement award with NASA Glenn Research Center (GRC) of Cleveland, Ohio. GRC also provides technology development for the ASC. The ASRG provides substantial efficiency and specific power improvements over radioisotope power systems of heritage designs.

The ASRG would use General Purpose Heat Source (GPHS) modules as the energy source and Stirling free-piston convertors to convert the heat to mechanical and then electrical energy. The current ASRG Engineering Unit uses the Sunpower-designed ASC. This convertor contains a nickel-based superalloy (MarM-247) heater head component (fig. 1 and ref. 4), a pressure vessel with maximum temperature at the hot end interface to the GPHS. This end of the heater head wall is thicker to reduce stresses induced by internal pressure; the wall thickness tapers down towards the other end, allowing higher stresses at the cooler metal temperatures and thus permitting higher system thermodynamic efficiency by reducing conduction losses.

Like most new technological advances, much effort is required to assure that the system operates reliably for its design lifetime; for the ASRG that design life is a minimum of 17 years of untended, fueled operation. A critical structural limit state for the high-temperature ASC heater head is creep deformation, the accumulation of inelastic strain under sustained loading over time (ref. 5). The typical creep deformation pattern exhibited by metals includes an initial short period of primary creep with higher creep strain rates. A long-duration secondary creep period follows; this period has a nearly linear, lower, steady-state creep rate. An accelerated creep rate defines the final, tertiary creep period that leads to rupture if not constrained. Because conventional engineering practices and available material property data are inadequate to assure reliable operation of the ASC MarM-247 heater head for its design life, a detailed life assessment effort is underway at GRC to evaluate accurately the heater head creep life margin.

The heater head creep life assessment includes a review of pertinent NASA design guidelines for creep and the development of additional reliability-related creep criteria. The design criteria rely on creep property data for the MarM-247 material obtained from an extensive series of uniaxial tests on thin specimens that comprise the same chemistry, microstructure, and heat treatment processing as the heater head itself. This GRC-led effort addresses a scarcity of openly available creep properties for MarM-247

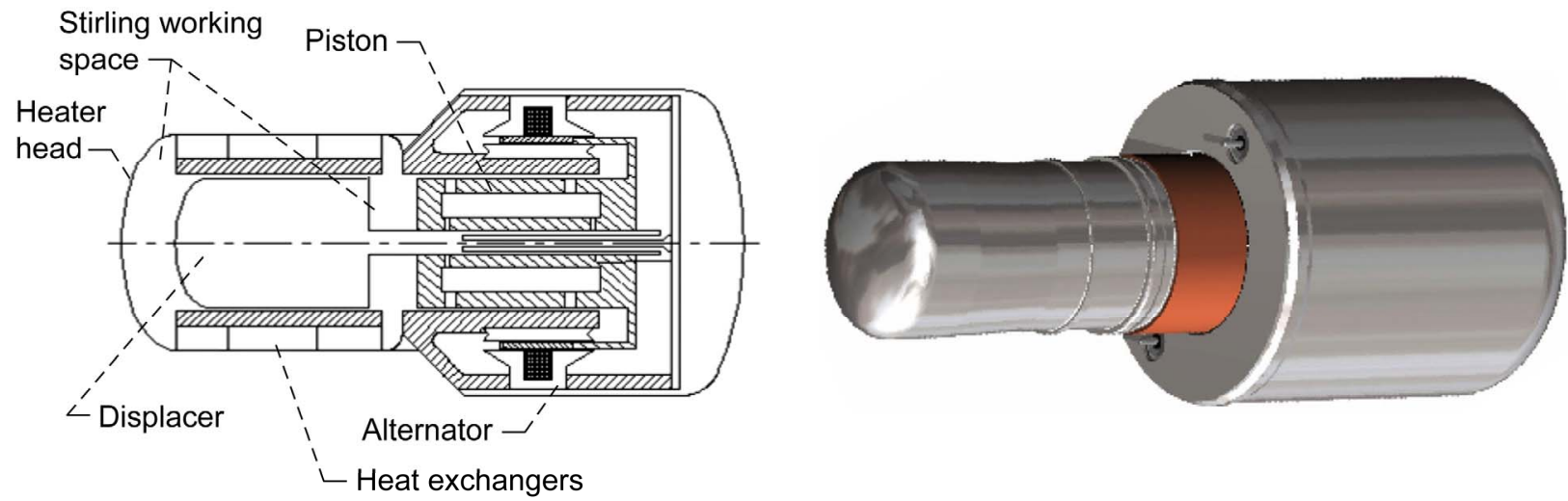

Figure 1.-Features of Sunpower 88 We ASC (ref. 4). The heater head shown on the left side is a pressure vessel that transfers heat from the GPHS to the contained working gas; the current ASC-E2 configuration is similar in construction. 
as well as for the virtual absence of understanding of the effect on creep properties due to very thin walls, fine grains, low stress levels, and high-temperature fabrication steps. The life assessment continues with a heater head deterministic analysis of processing-related residual stresses, followed by a durability analysis to evaluate the median creep life under operating conditions using nonlinear finite element analysis. The life assessment also includes a reliability analysis, which probabilistically evaluates the effect on creep life due to inherent uncertainties in (a) the creep behavior of the material itself, (b) manufacturing variations in the heater head wall thickness, and (c) measurement and control of the working gas pressure.

Finally, the life assessment approach concludes with a substantial activity for structural benchmark creep testing. This element provides high fidelity creep testing of prototypical heater head test articles that include the relevant material issues and multiaxial stress state. The testing applies the design operating temperature profile, or alternatively an accelerated temperature profile for quicker results, in a controlled laboratory environment. Accurate measurements of test article strains determine the time-dependent structural creep response. The approach uses the results to evaluate the reliability methodology and to calibrate the durability analysis, if needed.

The following presents an overview of life criteria development and the life assessment approach for the heater head. Then, the heater head structural benchmark creep test effort is described in detail, including the preliminary creep rate prediction methodology for the first test article, the experimental methods employed, unique test challenges, preliminary test results for the first test article, comparison to the analytical creep strain prediction, and other unexpected test findings. Lastly, a conclusion includes a description of the potential impact of the heater head creep life assessment and benchmark test results on the ASC program.

\section{Creep Life Assessment Methodology for the ASC Heater Head}

The ASC heater head under investigation is a variable-thickness, thin-walled cylindrical pressure vessel with an outer diameter of approximately 30 to $50 \mathrm{~mm}$. The wall is as thin as possible for resistance to longitudinal heat transfer to achieve low thermal losses, but thick enough to provide adequate strength to resist the internal operating pressure. The thin cylindrical wall stress field is biaxial, with circumferential (hoop) stress approximately twice the longitudinal stress. The hot end of the heater head is relatively thick, as the material strength and creep resistance are low at the elevated temperatures; the wall thickness tapers to the very thin cold end, where the material strength and creep resistance are higher. The general approach for the preliminary GRC life assessment of the heater head begins with a Sunpower preexisting ASC heater head geometry. It then evaluates that configuration for use with the hot end metal temperature equal to the MarM-247 maximum functional temperature of $850{ }^{\circ} \mathrm{C}$. The following paragraphs describe the GRC method for creep life assessment.

\section{A. Creep Criteria Development}

A review of NASA design requirements for creep provides limited guidance for the creep assessment of the ASC heater head. One pertinent technical standard (ref. 6) for spaceflight hardware offers the recommended guideline of a minimum service life factor (i.e., safety factor) of 4.0 on creep life for wellcharacterized materials. Unfortunately, the MarM-247 material of construction is not well characterized, and additionally there are expected future requirements based on the use of the GPHS and on potential mission reliability needs. This led to the development of reliability-based creep criteria. These criteria provide high assurance that heater head creep remains in the secondary creep regime and that stress redistribution at local areas of concentration can occur by creep deformation without leading to creep rupture. Specifically, analysis must demonstrate positive margins on limits placed upon through-thickness average creep strain, local creep strain, and the time to onset of tertiary creep. Deterministic results from finite element analysis of the heater head must show positive margins for the operating conditions and 17-year design life, and a probabilistic assessment must show positive margins on the same criteria to ensure a minimum reliability level of 0.999 . The limits are as follows: 
(1) The calculated through-thickness average creep strain at every location on the heater head must be equal to or less than the average creep strain at the onset of tertiary creep based on MarM-247 uniaxial creep test data. This criterion has the consequence of limiting heater head creep strains under "relaxed stresses" to the secondary creep regime and therefore restricts overall strains to the safer, more readily predictable, linear portion of creep behavior.

(2) Calculated peak local creep strains in the heater head must be equal to or less than 70 percent of the minimum observed creep failure strain from any uniaxial creep test of the MarM-247 material. This criterion allows localized moderately high stress areas to relax by creep deformation, while retaining a margin on the local creep strain in excess of the through-thickness average creep strain at each location.

(3) The calculated average time to the onset of tertiary creep at every through-thickness location on the heater head must be equal to or greater than the lower of 70 percent of the time to rupture, or the time to onset of tertiary creep based on the MarM-247 uniaxial creep test data. Similar to (1) above, this criterion assures that heater head creep occurs only in the secondary, linear creep regime, but the limit is in the time domain, rather than in the strain domain.

\section{B. Creep Life Assessment}

The heater head creep life assessment is a four-step approach. It begins with uniaxial creep tests of the ASC MarM-247 material: as described in the preceding paragraph, all creep life criteria rely on the test results. Currently, that testing is in progress, and analyses to date have used creep data from uniaxial tests performed on candidate materials and metallurgical grain sizes not necessarily used for the ASC heater head. A creep test matrix of at least 40 tests has been identified that minimally covers the range of temperatures and stresses included in critical areas of the heater head, with temperature acceleration for many tests to permit quicker results. As these test results become available, preferably for the flight heat of material, repeated and more accurate life assessment analyses are expected.

The second step of the creep life assessment is a deterministic durability analysis of the heater head under the operating conditions. However, the ASC heater head first endures several high-temperature processing stages in its manufacture, including diffusion bonding, brazing, and aging. These processes create a high residual stress state in the heater head due to the joining of materials with differences in coefficients of thermal expansion (CTEs), so the first phase of the deterministic analysis simulates these processes to determine the initial residual stress state. This ABAQUS finite element analysis in the time domain utilizes the materials' temperature-dependent CTEs and yield strengths, along with high temperature creep modeling using an Arrhenius-type exponential strain rate law. The second phase of the deterministic analysis applies this residual stress state along with the operating temperature and pressure conditions to derive the creep response over time. The second phase analysis uses a master curve creep model (ref. 7) for the MarM-247 material; the model is developed from the GRC uniaxial creep test results of MarM-247 and will be updated as additional creep test results become available. This timedomain analysis provides the median creep response of the heater head structure at important time increments, including the increment at the 17-year lifetime requirement, where it must show positive margins for the three creep criteria.

The third step of the life assessment analyzes the reliability of the heater head. This probabilistic assessment (ref. 7) simulates and analyzes uncertainties in the uniaxial creep test data, design parameters, and operating conditions of the heater head. Again, it must show positive margins on the same three creep criteria to ensure a minimum reliability level of 0.999 .

Finally, the fourth step of the assessment is a comprehensive heater head structural benchmark creep testing effort. Under this step, experiments place heater head test articles under both prototypical conditions and temperature-accelerated conditions with real-time monitoring of surface temperature, diametral strain, and internal pressure. Because the test articles are pressurized, a biaxial stress state exists similar to that in the complete ASC assembly heater head. Accelerated benchmark testing determines the effect of the biaxial stress field on creep response of the heater head and facilitates a comparison with the response predicted from uniaxial test data. In addition, the consequences of MarM-247 grain micro- 
structure on thin wall creep response, the effects from potentially inhomogeneous heat treatment (if any) on creep deformation, and the detection of any circumferentially directional creep caused by material processing or other mechanisms, are investigated. Both accelerated and prototypical benchmark testing creep strain results are compared to strains computed for the experimental conditions (including 3-sigma variations in temperature, pressure, and strain measurement) using the procedures outlined above for the second and third steps of creep life assessment. If the cumulative creep strains fall within a three-sigma range of the calculated median value, indicating approximately 0.999 reliability, then the tests verify the heater head creep life assessment methodology. If the cumulative creep strains do not, reinvestigation and fine-tuning of the analysis model will reflect more accurately the experimental setup and uncertainties. Any required systemic changes will be incorporated back into the heater head life assessment methodology.

The following presents more information about this fourth step for heater head creep life assessment, and presents the testing status and preliminary conclusions.

\section{Heater Head Structural Benchmark Creep Testing}

An earlier designed heater head vessel, produced to demonstrate machinability of the MarM-247 material, provided a ready test article for initial checkout of the GRC benchmark test rig. Although not fabricated with all of the now-required heat treatment processes that potentially affect creep behavior, nor composed of the probable final grain microstructure, it was a valuable test piece to prove efficacy of new heating and strain measurement methods at the test facility. The chosen temperature-accelerated "cascade" testing method (described under paragraph B of this section) provided early results.

\section{A. Preliminary Creep Rate Prediction for Test Article "M"}

Because the test article (here named "M") was of a large-grain microstructure MarM-247 not typical for the likely ASC heater head final grain microstructure, the master curve creep model developed for heater head creep life assessment did not apply. To make predictions of the creep response in order to select sensitivity of the test instrumentation, an abbreviated preliminary method was derived specifically for test article "M" to predict the diametral creep strain rate under the test conditions. Creep strain rate is the basic output of the benchmark test, as opposed to time to creep rupture, due to the potential hazard of rupture of the pneumatically pressurized vessel. The method relies on limited uniaxial creep test data available for large-grain MarM-247 from GRC-performed tests during the material selection process.

Akin to formulation of the Larson-Miller Parameter that relates temperature and rupture time to stress, this method calculates a new parameter dependent on the temperature and observed secondary steady state creep strain rate of the test specimen. The parameter includes constants such that the Pearson product moment correlation coefficient value $\left(\mathrm{R}^{2}\right)$ to a linear fit against stress is at a maximum for the uniaxial creep test data. Equation (1) describes the dependence of this Creep Strain Rate Parameter $(\mathrm{CSRP})$ on temperature $(T)$, measured in ${ }^{\circ} \mathrm{C}$, and steady state creep strain rate $(\dot{\varepsilon})$ measured in $\mathrm{mm} / \mathrm{mm}$ per hour.

Then the best straight line fit for the available thirteen large-grain MarM-247 creep rate tests is produced described by in equation (2), for stress $(\sigma)$ in MPa; figure 2 shows the line graphically. The relationships of equation (1) and (2) provided the basis for estimating the creep strain response of largegrain MarM-247 test article "M"; paragraph D2 provides that prediction along with the test results.

$$
\begin{gathered}
\operatorname{CSRP}=f_{1}(T, \log \dot{\varepsilon}) \\
\sigma=f_{2}(\mathrm{CSRP})
\end{gathered}
$$




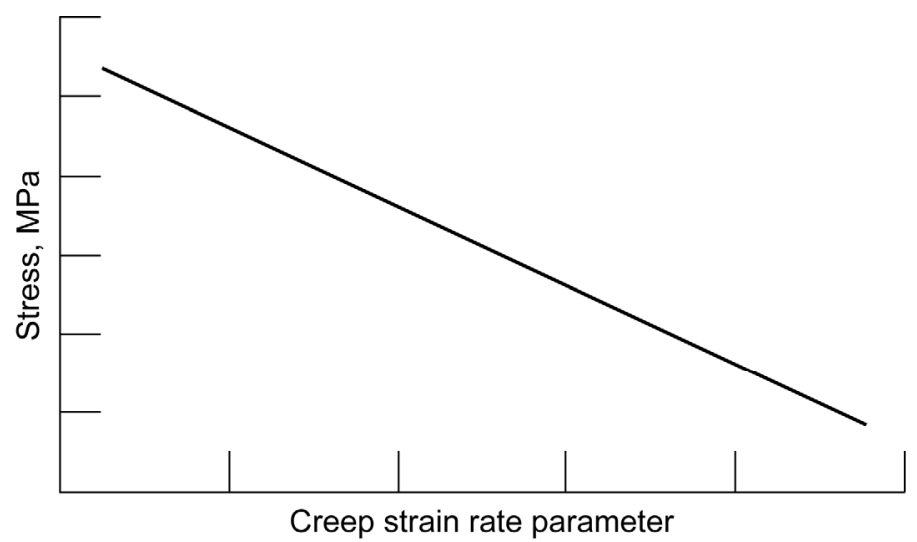

Figure 2.-Large-grain MarM-247 creep test data fit. The line shows a linear fit for stress as a function of the creep strain rate parameter for large-grain MarM-247 uniaxial creep tests.

\section{B. Benchmark Creep Test Experimental Method}

The primary objective of structural benchmark creep testing is to determine the creep response of the heater head structure by measurement of the heater head circumferential secondary (steady state) creep strain rate. A secondary objective is quantitative observation of structural creep strain deformation in the initial primary creep phase. Additionally for accelerated tests, the observation continues through to the onset of tertiary creep.

For both prototypical and accelerated cases, the temperature profile along the test article wall does not vary over time, whereas stress level varies by wall thickness in the gage area with test article internal pressure held constant at the design level. Prototypical testing applies the design operating temperature distribution to the test article, whereas the accelerated case extends the $850{ }^{\circ} \mathrm{C}$ hot end maximum temperature areas toward the cold end using a "cascade" creep test method (ref. 8). In this manner, the thinner wall, higher stressed areas are temperature-accelerated to produce larger creep strains for faster analysis. For prototypical testing, the critical creep strain measurement location may be located at the thick end of the tapered wall, where high creep strain rates may exist due to high temperature, even though stresses are low. For the accelerated testing case, the gage area of interest extends over a large portion of the tapered wall due to the combined effect of elevated temperature and stress conditions.

The heater head structural benchmark creep test facility currently includes two test rigs. Each rig (fig. 3) incorporates a digital control and data acquisition system, a bottle-fed closed argon pressurization system, an induction heater with custom silicon carbide susceptor, a closed-loop cooling system, complex temperature sensing devices, diametral extensometers, and a pair of vertically translating laser micrometers. Reference 8 provides further discussion of test apparatus. For prototypical tests, the inductively heated susceptor is in a raised position, with cooling water throttled to produce the design operating temperature profile to the extent possible; extensometer strain measurements are concentrated at a critical location on the tapered wall. For accelerated testing, the susceptor is at a lower level toward the tapered wall thin end, and laser scan measurements for calculation of diametral strains along the entire taper take greater importance. During testing, the extensometers provide continuous strain measurement at discrete points, whereas intermittent full-length laser scans allow creep characterization across the stress spectrum at selected time increments. 


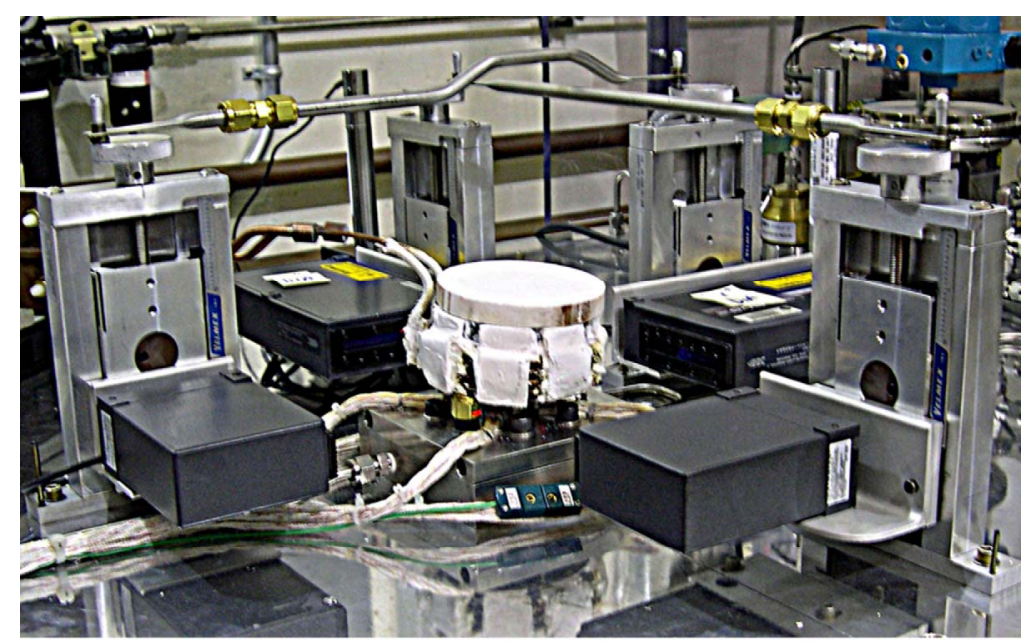

Figure 3.-Heater head benchmark creep test rig. This photo shows an insulated susceptor enveloping test article "M," which is surrounded by laser micrometers (black boxes) mounted on vertical positioning stages.

\section{Benchmark Test Challenges}

Several test challenges remain that impact test operations or usefulness of results if not surmounted. First challenge is the ability to obtain temperature uniformity for accelerated testing over the large heater head wall area using an inductively heated susceptor. Test article " $M$ " demonstrated promising results as described in paragraph $\mathrm{D}$, but additional tuning and induction coil design work is required to obtain more uniform temperature along the test article wall.

Another challenge is maintaining the cold-end o-ring seal temperature at a level that avoids damage. This was possible for test article "M," but with the desired increased temperature at that end in future testing, there is a possible need for additional water-cooling at the cold-end flange.

Repeatable, high accuracy diameter measurements are required to resolve the extremely small creep strains. The selected instrumentation specifications are adequate, but the real-world effects of electronic noise, variable room temperature, and scatter in control of temperature and pressure all affect the readings. The desired strain resolution requires diameter measurement precision to be in the range of $0.5 \mathrm{~mm}$.

A large challenge is accounting for oxide layer thickness on the MarM-247 heater head outside diameter during the in-air benchmark tests. Although expected to be of minimal effect with extensometer measurements, this growth is inseparable from creep strain deformation using the laser micrometers. An oxide layer study is underway at GRC to provide an analytical method to distinguish creep strains from the effects of oxidation. In addition, post-test destructive examination of the test article will reveal actual accumulated oxide layer thickness.

\section{Test Results for Test Article "M"}

Test article " $M$ " provided checkout of a newly assembled benchmark test rig and its pressurization, heating, cooling, strain measurement, and data acquisition systems (fig. 4). Extensometers were not available for this test but received shortly thereafter. All of the test systems proved highly functional, but full verification or configuration of some systems was incomplete at the time of test termination. Notable is incomplete tuning of the susceptor and insulation to provide the desired accelerated test temperature profile, as well as incomplete tuning for the prototypical temperature distribution case. 


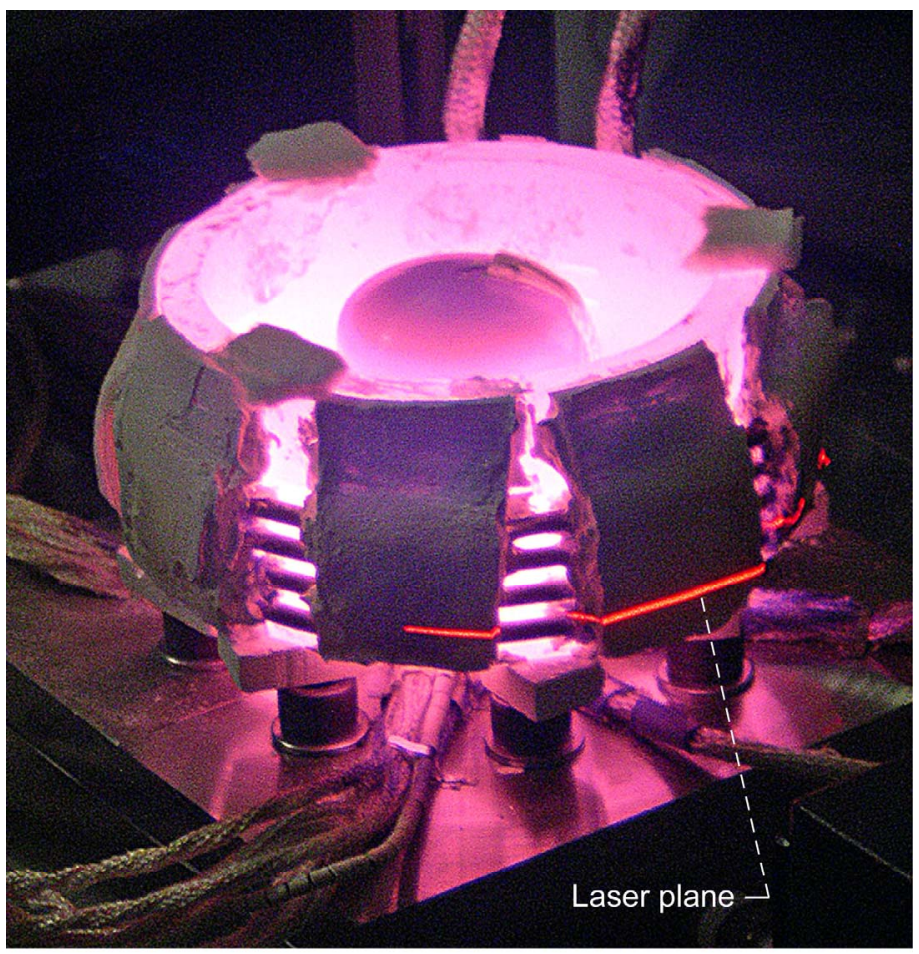

Figure 4.-Test article " $\mathrm{M}$ " at $850^{\circ} \mathrm{C}$. This photo shows a later heating case with the susceptor "lid" insulation removed to decrease upper temperatures; the horizontal red line is the collimated laser plane illuminating insulation between window slots.

\section{Test Conditions}

The internal test pressure was $3.55 \mathrm{MPa}$, held with the argon pressurization system. The temperature profile goal was to maintain $850{ }^{\circ} \mathrm{C}$ throughout most of the tapered wall area, but that performance was not achieved (fig. 5). The test ran in long continuous periods for a total of approximately $850 \mathrm{hr}$ at higher temperatures; earlier short test durations at $700{ }^{\circ} \mathrm{C}$ or lower contributed little to creep deformation.

\section{Test Measurements and Results}

As described previously, extensometers were unavailable for this test article, so all diameter measurements and calculated diametral strains relied on laser micrometer readings alone. To determine elastic diametral strains, the test article's elastic axial growth incurred upon pressurization $\left(\Delta_{1}\right.$ in fig. 6(a)) was first subtracted from the axial position of the laser plane at each measurement location; this allowed comparison of diameters at identical physical locations on the heater head wall. This calculation prorated the measured elastic axial deformation along the scanned length based on the mechanics of materials solution for the incident wall thickness, with prorating identical to zero at the top of the tapered wall (fig. 6(b)). This location appears noticeably in the scans by the transition from an inclined to a vertical wall. Following the prorating calculation, the procedure subtracts initial, unpressurized diameter scan values from those values recorded at the test pressure, and then divides that difference by the diameter to arrive at elastic diametral strain. Figure 7 shows the successful results of using this procedure for initial pre-test room temperature laser scans along two perpendicular axes at ambient pressure and then at test pressure. The figure shows the laser-derived experimental strains compared graphically to the average readings from six test article strain gages located away from structural discontinuities, and to analytical values based on the mechanics of materials solution for the same pressure loading. 


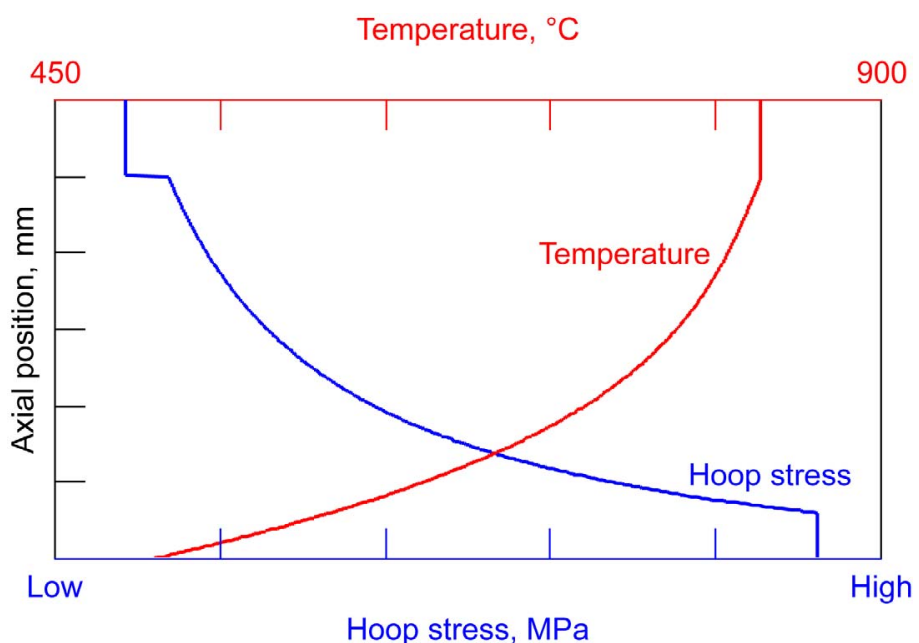

Figure 5.-Accelerated test conditions. Relative temperature and stress conditions for test article "M"; step in stress indicate the axial position at the top of the tapered wall.

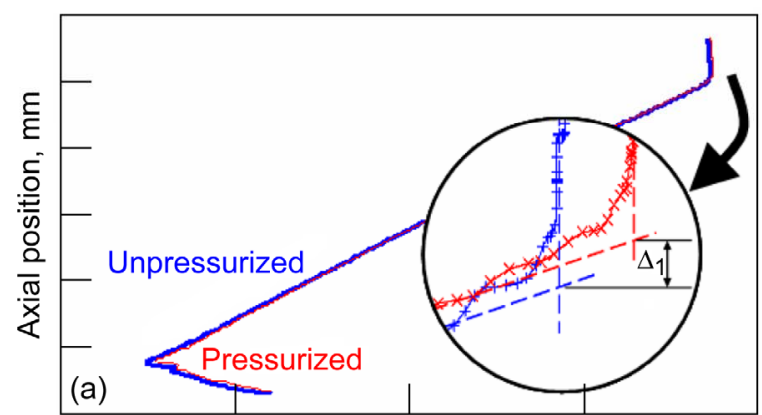

Diameter, $\mathrm{mm}$

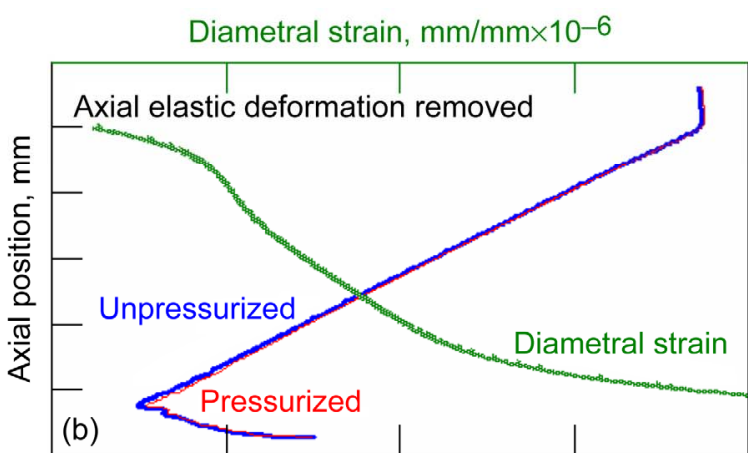

Diameter, $\mathrm{mm}$

Figure 6.-Calculation of elastic diametral strain. (a) Shows the axial growth due to test pressure recorded at the top of the wall taper. (b) Shows the elastic diametral strain calculated from the growth of the tapered wall diameters.

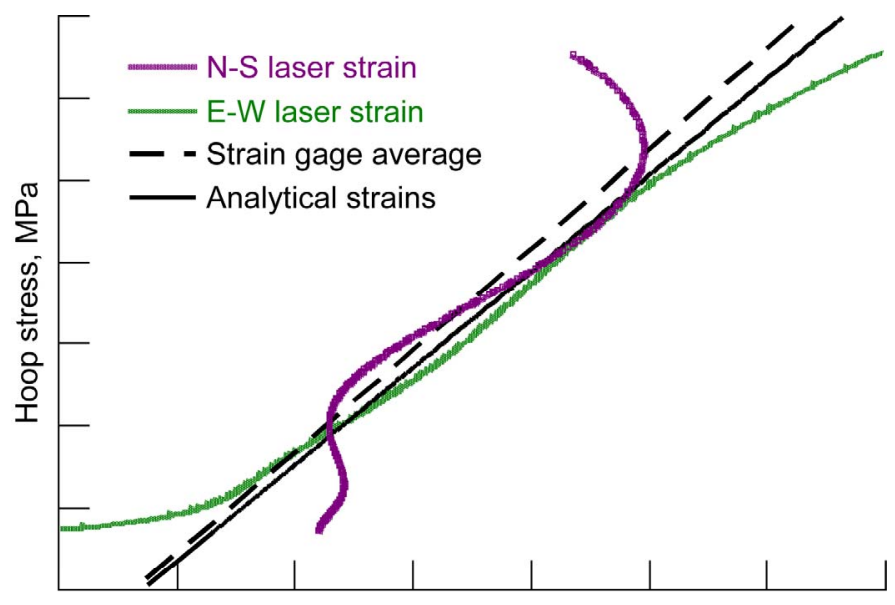

Diametral strain, $\mathrm{mm} / \mathrm{mm} \times 10^{-6}$

Figure 7.-Measured elastic strain compared to prediction. Elastic strains,calculated from diameter dilation measured by laser scans while the test article was pressurized, compared well with strain gage readings and with the predicted values. 


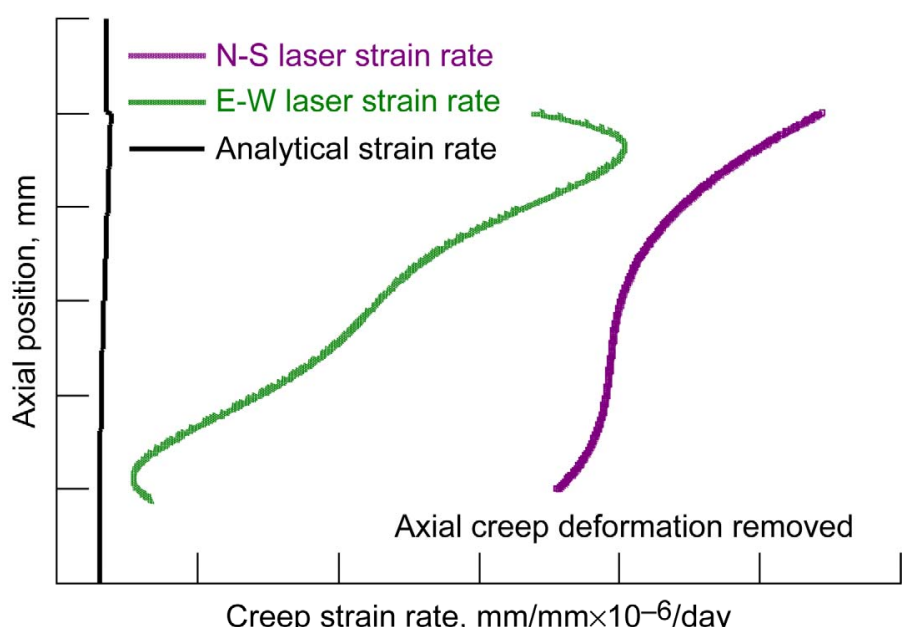

Figure 8.-Measured creep strain compared to prediction. Average creep strain rates during approximately $850 \mathrm{hr}$ of testing, calculated from diameter dilation measured by laser scans at test initiation until test completion, compared to the predicted values.

Diametral creep strains were determined similarly, by subtracting the initial geometry from the deformed geometry following testing. However, in this case the cause of axial growth measured by the laser scans was creep incurred during testing, rather than by elastic deformation as in the previous case. Therefore, the prorating was based on the incident stress and temperature conditions and using equations (1) and (2), scaled to match the measured axial creep. Figure 8 provides a summary of the creep rate results expressed as creep strain per day, for the two laser axes based on unpressurized pre-test scans and un-pressurized post-test scans; this captures the cumulative effect of creep for the entire test period. Future testing will characterize the changing apparent strain rates over time by including intermediate laser scan data.

\section{Test Findings}

Laser micrometer measurements provide a reasonable quantification of heater head test article strains as verified by the room temperature elastic strain comparison shown in figure 7, where the analytical solution is straightforward and verified by the use of traditional strain gages. However, the strain quantification is very dependent on accurately measuring and prorating the accompanying axial extension. To facilitate these in future testing, geometric markers placed near the top and bottom extents of the scanned area will provide easier observation of the axial extension.

As described previously in section II, part B, the fourth step of the creep life assessment is to compare the experimental creep deformation in structural benchmark tests with the prediction based on a probabilistic analysis of the specific test conditions. Here, that step was excluded due to the preliminary nature of the test, and the fact that the test article's material of construction was not well characterized in a more complete material model.

Diameter growth between the start and the end of testing has been labeled "creep strain," but in fact, the measurement may include other mechanisms heretofore not considered. Important among those must be oxide layer growth. As all heater head benchmark testing performed is in air, the MarM-247 test article surface oxidizes at the test temperature incurred. A preliminary post-test metallographic study of oxide layer growth on three large-grain MarM-247 uniaxial creep test specimens quantified the effect (fig. 9). Exposure times at $850{ }^{\circ} \mathrm{C}$ and in air ranged from approximately 1000 to $4400 \mathrm{hr}$. From this data, an equivalent "strain" rate of $10 \times 10^{-6} \mathrm{~mm} / \mathrm{mm} /$ day calculated for all diameters exposed to $850{ }^{\circ} \mathrm{C}$ could apply to test article "M." That is about the magnitude of creep strains shown in figure 8. 


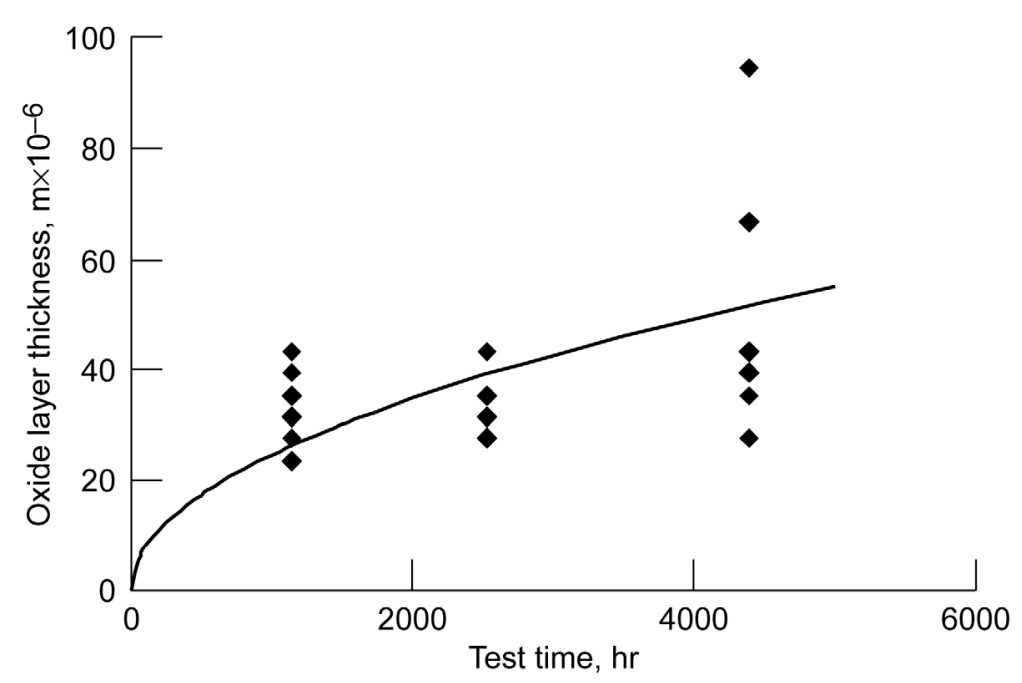

Figure 9.-Oxide layer growth for MarM-247. This plot shows preliminary characterization of oxide layer growth for large-grain MarM-247 at $850^{\circ} \mathrm{C}$.

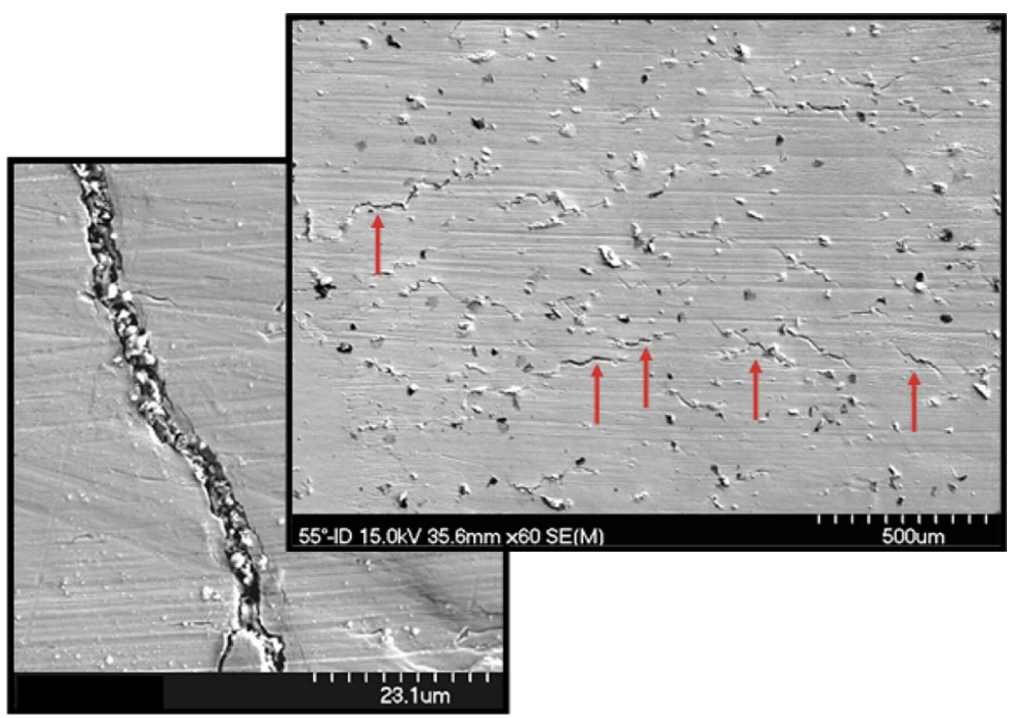

Figure 10.-Cracking observed in test article "M". Red arrows indicate location of micro-cracks in the embrittled zone.

The benchmark test of test article "M" terminated when several leaks though the thin lower portion occurred. Metallographic inspection of the inside surface at the through cracks showed the gathering of many fine particles (fig. 10, lower left photomicrograph). Further inspection in the area of leaks revealed the widespread presence of more particles as well as numerous smaller cracks in a $5 \mathrm{~mm}$ wide circumferential band (fig. 10, upper right photomicrograph). Bending a sample of the material showed that it was embrittled on the inside surface by the production of extensive crazing cracking when in tension; the outer surface, where the particles were not observed, remained ductile. Chemical analysis of the particles determined that their composition was elemental sulfur, a corrosive agent to the nickel-based MarM-247 superalloy. It was later determined that an alumina silicate plug, used to fill the majority of the volume of the test article in order to minimize energy stored in the compressed gas, was a likely contributor of the elemental sulfur. This unfired ceramic material had 6 percent trace elements in its specification, which may account for all of the sulfur present. Chemical analysis of the ceramic material 
before and after use in the benchmark test shows a loss of the sulfur spectra signature; sulfur has a melting point of $115^{\circ} \mathrm{C}$ and a boiling point of $445^{\circ} \mathrm{C}$ at atmospheric pressure, well below the test temperatures encountered. At the time of this writing, an investigation of other possible sources of sulfur is ongoing, including examining the argon gas used to provide pneumatic pressure, and the elastomeric o-ring used at the test article's cold end to provide the pressure seal. For future testing, pre-fired pure alumina will be used as the plug material to eliminate that sulfur source.

\section{Conclusion}

The Glenn Research Center is conducting a robust creep life assessment of the heater head component in the Advanced Stirling Convertor program. The assessment has identified three creep response criteria to prove component lifetime based on results from uniaxial creep testing of the heater head material. The heater head component must meet these criteria with high reliability as determined by probabilistic analysis. Further, structural benchmark testing of the heater head validates this complex analytical effort.

A trial test of a preliminary heater head test article verified the benchmark testing methodology, itself quite complicated. The experience gained by this test was very valuable to ensure successful future testing. The test proved the effectiveness of the unique argon pressurization system, inductively heated susceptor furnace, and robust data acquisition system developed for the test rig. It also proved the viability of using commercially available laser micrometers to measure heater head diameters with very high precision. A method to convert the laser scans to heater head strains was developed and proved to be accurate by comparison with strain gage data and with strength of materials calculations.

Based on the trial test experience, one change to the benchmark procedures for future testing is the use of geometric markers to ease identification of the upper and lower tapered wall limits for laser scan use. A second change is use of contact extensometers for real-time creep strain measurement. Additionally, further experimental study of oxide layer growth in MarM-247 will enable temperature and time-dependent prediction of the contribution of oxide scale to the diameter growth measurements; incorporation of post-test metallographic inspection of test article material to measure cumulative oxide growth will verify that prediction. Lastly, pre-test analysis of materials used in testing will assure the absence of sulfur, which can contribute to degradation of MarM-247 properties.

In general, the elastic response of the trial test article was proportional to stress as expected. The temperature field rather than the stress level dominated the apparent creep response sensitivity, but the effect of oxide layer growth may make this evaluation questionable; for the trial test, experimental quantification of the oxide scale was not performed. The creep results show that the average response is likely in agreement with predicted creep strain rates if the oxide scale growth is accounted, and the high scatter common in experimental creep results of materials is considered.

Completion of the full creep life assessment as proposed for the heater head will be a large positive impact for proving reliability of the Advanced Stirling Convertor for use in potential future lunar applications, Mars rovers, and deep space missions. Structural benchmark testing of the heater head is a valuable and necessary component of that assessment, and trial testing as described verified its successful performance. This work enables the use of the high-temperature, advanced nickel-based superalloy MarM-247, overcoming the lack of available low stress, long-term creep data for the material, and providing the opportunity for greatly improved convertor efficiency with high durability and reliability.

\section{References}

1. Shaltens, R.K., and Wong, W.A., “Advanced Stirling Technology Development at NASA Glenn Research Center," NASA/TM-2007-214930, 2007.

2. Wong, W.A., Anderson, D.J., Tuttle, K.L., and Tew, R.C., "Status of NASA's Advanced Radioisotope Power Conversion Technology Research and Development," Space Technology and Applications International Forum (STAIF-2006), edited by M.S. El-Genk, AIP Conference Proceedings 813, Melville, New York, 2006, pp. 340-347. 
3. Schreiber, J.G. and Thieme, L.G. "GRC Supporting Technology for NASA's Advanced Stirling Radioisotope Generator (ASRG)," Space Technology and Applications International Forum (STAIF2008), edited by M.S. El-Genk, AIP Conference Proceedings 969, Melville, New York, 2008, pp. 582-592.

4. Chan, J., Wood, J.G., and Schreiber, J.G., "Development of Advanced Stirling Radioisotope Generator for Space Exploration,” NASA/TM-2007-214806, 2007.

5. Bowman, R.R., "Long-Term Creep Assessment of a Thin-Walled Inconel 718 Stirling PowerConvertor Heater Head," Proceedings of 36th Intersociety Energy Conversion Engineering Conference (IECEC), vol. 1, AIAA Conference Proceedings 2001-CT-33, Reston, VA, 2001, pp. 435-440.

6. Anonymous, "Structural Design and Test Factors of Safety for Spaceflight Hardware," NASA Technical Standard STD-5001, Marshall Space Flight Center, Huntsville, AL, 1996.

7. Shah, A.R., Korovaichuk, I., Krause, D.L., and Kalluri, S., "Advanced Stirling Convertor Heater Head Durability and Reliability Quantification," Proceedings of the $6^{\text {th }}$ International Energy Conversion Engineering Conference (IECEC), AIAA Conference Proceedings 2008-5772, Reston, VA, to be published 2008.

8. Krause, D.L., Kalluri, S., and Bowman, R.R., "Structural Benchmark Testing for Stirling Convertor Heater Heads," Space Technology and Applications International Forum (STAIF-2007), edited by M.S. El-Genk, AIP Conference Proceedings 880, Melville, NY, 2007, pp. 297-304. 


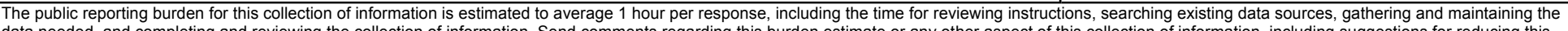

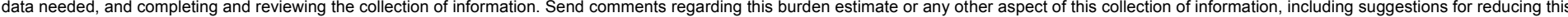

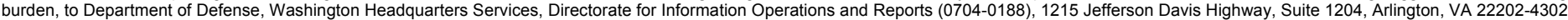

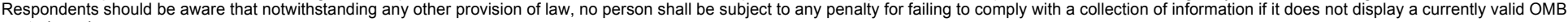
control number.

PLEASE DO NOT RETURN YOUR FORM TO THE ABOVE ADDRESS.
1. REPORT DATE (DD-MM-YYYY)
2. REPORT TYPE
3. DATES COVERED (From - To)
01-11-2008

Technical Memorandum

\section{TITLE AND SUBTITLE}

Structural Benchmark Creep Testing for the Advanced Stirling Convertor Heater Head

5a. CONTRACT NUMBER

5b. GRANT NUMBER

5c. PROGRAM ELEMENT NUMBER

6. AUTHOR(S)

Krause, David, L.; Kalluri, Sreeramesh; Bowman, Randy, R.; Shah, Ashwin, R.

5d. PROJECT NUMBER

5e. TASK NUMBER

5f. WORK UNIT NUMBER

WBS 138494.04.01.01

7. PERFORMING ORGANIZATION NAME(S) AND ADDRESS(ES)

National Aeronautics and Space Administration

John H. Glenn Research Center at Lewis Field

Cleveland, Ohio 44135-3191

\section{SPONSORING/MONITORING AGENCY NAME(S) AND ADDRESS(ES)}

National Aeronautics and Space Administration

Washington, DC 20546-0001

\section{PERFORMING ORGANIZATION}

REPORT NUMBER

E-16603

\section{DISTRIBUTION/AVAILABILITY STATEMENT}

Unclassified-Unlimited

Subject Categories: 26 and 39

Available electronically at http://gltrs.grc.nasa.gov

This publication is available from the NASA Center for AeroSpace Information, 301-621-0390

\section{SUPPLEMENTARY NOTES}

\section{ABSTRACT}

The National Aeronautics and Space Administration (NASA) has identified the high efficiency Advanced Stirling Radioisotope Generator (ASRG) as a candidate power source for use on long duration Science missions such as lunar applications, Mars rovers, and deep space missions. For the inherent long life times required, a structurally significant design limit for the heater head component of the ASRG Advanced Stirling Convertor (ASC) is creep deformation induced at low stress levels and high temperatures. Demonstrating proof of adequate margins on creep deformation and rupture for the operating conditions and the MarM- 247 material of construction is a challenge that the NASA Glenn Research Center is addressing. The combined analytical and experimental program ensures integrity and high reliability of the heater head for its $17-y e a r$ design life. The life assessment approach starts with an extensive series of uniaxial creep tests on thin MarM-247 specimens that comprise the same chemistry, microstructure, and heat treatment processing as the heater head itself. This effort addresses a scarcity of openly available creep properties for the material as well as for the virtual absence of understanding of the effect on creep properties due to very thin walls, fine grains, low stress levels, and high-temperature fabrication steps. The approach continues with a considerable analytical effort, both deterministically to evaluate the median creep life using nonlinear finite element analysis, and probabilistically to calculate the heater head's reliability to a higher degree. Finally, the approach includes a substantial structural benchmark creep testing activity to calibrate and validate the analytical work. This last element provides high fidelity testing of prototypical heater head test articles; the testing includes the relevant material issues and the essential multiaxial stress state, and applies prototypical and accelerated temperature profiles for timely results in a highly controlled laboratory environment. This paper focuses on the last element and presents a preliminary methodology for creep rate prediction, the experimental methods, test challenges, and results from benchmark testing of a trial MarM-247 heater head test article. The results compare favorably with the analytical strain predictions. A description of other test findings is provided, and recommendations for future test procedures are suggested. The manuscript concludes with describing the potential impact of the heater head creep life assessment and benchmark testing effort on the ASC program.

\section{SUBJECT TERMS}

Stirling cycle; Mechanical properties; Creep rupture strength; Steady state creep; Strain rate; Deformation; Life (durability); Pressure vessels; Nickel alloys; Heat treatment

\begin{tabular}{|c|c|c|c|c|c|}
\hline 16. SECURI & ASSIFICATION & & 17. LIMITATION OF & 18. NUMBER & 19a. NAME OF RESPONSIBLE PERSON \\
\hline $\begin{array}{l}\text { a. REPORT } \\
U\end{array}$ & $\begin{array}{l}\text { b. ABSTRACT } \\
U\end{array}$ & $\begin{array}{l}\text { c. THIS } \\
\text { PAGE } \\
\text { U }\end{array}$ & UU & $\begin{array}{c}\text { PAGES } \\
19\end{array}$ & $\begin{array}{l}\text { 19b. TELEPHONE NUMBER (include area code) } \\
301-621-0390\end{array}$ \\
\hline
\end{tabular}



